\title{
A Strong Form of Lindelof Spaces
}

\author{
${ }^{*}$ C.Duraisamy ${ }^{* *}$ R.Vennila \\ *Department of Mathematics, Kongu Engineering College, Perundurai, Erode-638052 \\ ** Department of Mathematics, SriGuru Institute of Technology, Varathaiyangar Palayam, Coimbatore-641110
}

Abstract: In this paper, we introduce and investigate a new class of set called $\omega-\lambda$-open set which is weaker than both $\omega$-open and $\lambda$-open set. Moreover, we obtain the characterization of $\lambda$-Lindelof spaces.

Keywords: Topological spaces, $\lambda$-open sets, $\lambda$-Lindelof spaces. 2000 Mathematics Subject Classification: 54C05, 54C08, 54C10.

\section{Introduction And Preliminaries}

Throughout this paper $(\mathrm{X}, \tau)$ and $(\mathrm{Y}, \sigma)$ stand for topological spaces with no separation axioms assumed, unless otherwise stated. Maki [3] introduced the notion of $\Lambda$-sets in topological spaces. A $\Lambda$-set is a set A which is equal to its kernel, that is, to the intersection of all open supersets of A. Arenas et.al. [1] Introduced and investigated the notion of $\lambda$-closed sets by involving $\Lambda$-sets and closed sets. Let $\mathrm{A}$ be a subset of a topological space $(\mathrm{X}, \tau)$. The closure and the interior of a set $\mathrm{A}$ is denoted by $\mathrm{Cl}(\mathrm{A}), \operatorname{Int}(\mathrm{A})$ respectively. $\mathrm{A}$ subset $\mathrm{A}$ of a topological space $(\mathrm{X}, \tau)$ is said to be $\lambda$-closed [1] if $\mathrm{A}=\mathrm{B} \cap \mathrm{C}$, where $\mathrm{B}$ is a $\Lambda$-set and $\mathrm{C}$ is a closed set of $\mathrm{X}$. The complement of $\lambda$-closed set is called $\lambda$-open [1]. A point $x \in \mathrm{X}$ in a topological space $(\mathrm{X}, \tau)$ is said to be $\lambda$-cluster point of $\mathrm{A}[2]$ if for every $\lambda$-open set $\mathrm{U}$ of $\mathrm{X}$ containing $x, \mathrm{~A} \cap \mathrm{U} \neq \phi$. The set of all $\lambda$-cluster points of $\mathrm{A}$ is called the $\lambda$-closure of $\mathrm{A}$ and is denoted by $\mathrm{Cl}_{\lambda}(\mathrm{A})$ [2]. A point $x \in \mathrm{X}$ is said to be the $\lambda$-interior point of $\mathrm{A}$ if there exists a $\lambda$-open set $\mathrm{U}$ of $\mathrm{X}$ containing $x$ such that $\mathrm{U} \subset \mathrm{A}$. The set of all $\lambda$-interior points of $A$ is said to be the $\lambda$-interior of $A$ and is denoted by $\operatorname{Int}_{\lambda}(\mathrm{A})$. A set $\mathrm{A}$ is $\lambda$-closed (resp. $\lambda$-open) if and only if $\mathrm{Cl}_{\lambda}(\mathrm{A})=\mathrm{A}\left(\right.$ resp. $\left.\operatorname{Int}_{\lambda}(\mathrm{A})=\mathrm{A}\right)[2]$.

The family of all $\lambda$-open (resp. $\lambda$-closed) sets of $X$ is denoted by $\lambda O(X)$ (resp. $\lambda C(X))$. The family of all $\lambda$-open (resp. $\lambda$-closed) sets of a space $(\mathrm{X}, \tau)$ containing the point $x \in \mathrm{X}$ is denoted by $\lambda \mathrm{O}(\mathrm{X}, x)$ (resp. $\lambda \mathrm{C}(\mathrm{X}$, $x)$ ).

\section{II. $\quad \omega-\lambda$-OPEN SETS}

Definition 2.1: A subset $\mathrm{A}$ of a topological space $\mathrm{X}$ is said to be $\omega-\lambda$-open if for every $x \in \mathrm{A}$, there exists a $\lambda$-open subset $\mathrm{U}_{x} \in \mathrm{X}$ containing $x$ such that $\mathrm{U}_{x}-\mathrm{A}$ is countable. The complement of an $\omega-\lambda$-open subset is said to be $\omega-\lambda$-closed.

Proposition 2.2: Every $\lambda$-open set is $\omega-\lambda$-open. Converse not true.

Corollary 2.3: Every open set is $\omega-\lambda$-open, but not conversely.

Proof: Follows from the fact that every open set is $\lambda$-open.

Lemma 2.4: For a subset of a topological space, both $\omega$-openness and $\lambda$-openness imply $\omega-\lambda$-openness.

Proof: (i) Assume A is $\omega$-open then, for each $x \in \mathrm{A}$, there is an open set containing $x$ such that $\mathrm{U}_{x}-\mathrm{A}$ is countable. Since every open set is $\lambda$-open, $\mathrm{A}$ is $\omega-\lambda$-open. (ii) Let $\mathrm{A}$ be $\omega-\lambda$-open. For each $x \in \mathrm{A}$, there exists a $\lambda$-open set $\mathrm{U}_{x}=\mathrm{A}$ such that $x \in \mathrm{U}_{x}$ and $\mathrm{U}_{x}-\mathrm{A}=\phi$.Therefore, $\mathrm{A}$ is $\omega$ - $\lambda$-open.

Example 2.5: Let $X=\{a, b, c\}, \tau=\{\phi,\{a\}, X\}$, then $\{b\}$ is $\omega$-open but not $\lambda$-open (since $X$ is a countable set).

Example 2.6: Let $X=R$ with the usual topology. Let $A=Q$ be the set of all rational numbers. Then $A$ is $\lambda$-open but it is not $\omega$-open.

Lemma 2.7: A subset $\mathrm{A}$ of a topological space $\mathrm{X}$ is $\omega-\lambda$-open if and only if for every $x \in \mathrm{A}$, there exists a $\lambda$-open subset $\mathrm{U}$ containing $x$ and a countable subset $\mathrm{C}$ such that $\mathrm{U}-\mathrm{C} \subset \mathrm{A}$. 
Proof: Let $\mathrm{A}$ be $\omega-\lambda$-open and $x \in \mathrm{A}$, then there exists a $\lambda$-open subset $\mathrm{U}_{x}$ containing $x$ such that $n\left(\mathrm{U}_{x}-\mathrm{A}\right)$ is countable. Let $\mathrm{C}=\mathrm{U}_{x}-\mathrm{A}=\mathrm{U}_{x} \cap(\mathrm{X}-\mathrm{A})$. Then $\mathrm{U}_{x}-\mathrm{C} \subset \mathrm{A}$. Conversely, let $x \in \mathrm{A}$. Then there exists a $\lambda$-open subset $\mathrm{U}_{x}$ containing $x$ and a countable subset $\mathrm{C}$ such that $\mathrm{U}_{x}-\mathrm{C} \subset \mathrm{A}$. Thus, $\mathrm{U}_{x}-\mathrm{A} \subset \mathrm{C}$ and $\mathrm{U}_{x}-\mathrm{A}$ is countable.

Theorem 2.8: Let $\mathrm{X}$ be a topological space and $\mathrm{C} \subset \mathrm{X}$ If $\mathrm{C}$ is $\lambda$-closed, then $\mathrm{C} \subset \mathrm{K} \cup \mathrm{B}$ for some $\lambda$-closed subset $\mathrm{K}$ and a countable subset $\mathrm{B}$.

Proof: If $\mathrm{C}$ is $\lambda$-closed, then $\mathrm{X}-\mathrm{C}$ is $\lambda$-open and hence for every $x \in \mathrm{X}-\mathrm{C}$, there exists a $\lambda$-open set $\mathrm{U}$ containing $x$ and a countable set $B$ such that $U-B \subset X-C$. Thus $\mathrm{C} \subset \mathrm{X}-(\mathrm{U}-\mathrm{B})=\mathrm{X}-(\mathrm{U} \cap(\mathrm{X}-\mathrm{B}))=\mathrm{X}-(\mathrm{U} \cup \mathrm{B})$. Let $\mathrm{K}=\mathrm{X}-\mathrm{U}$. Then $\mathrm{K}$ is $\lambda$-closed such that $\mathrm{C} \subset \mathrm{K} \cup \mathrm{B}$.

Corollary 2.9 The intersection of an $\omega-\lambda$-open set with an open set is $\omega-\lambda$-open.

Question: Does there exist an example for the intersection of $\omega-\lambda$-open sets is $\omega-\lambda$-open?

Proposition 2.10: The union of any family of $\omega-\lambda$-open sets is $\omega-\lambda$-open.

Proof: If $\left\{\mathrm{A}_{\alpha}: \alpha \in \Lambda\right\}$ is a collection of $\omega-\lambda$-open subsets of $\mathrm{X}$, then for every $x \in \bigcup_{\alpha \in \Lambda} \mathrm{A}_{\alpha}, x \in \mathrm{A}_{\gamma}$ for some $\gamma \in \Lambda$. Hence there exists a $\lambda$-open subset $\mathrm{U}$ of $\mathrm{X}$ containing $x$ such that $\mathrm{U}-\mathrm{A}_{\gamma}$ is countable. Now $\mathrm{U}-\bigcup_{\alpha \in \Lambda} \mathrm{A}_{\alpha} \subset \mathrm{U}-\mathrm{A}_{\gamma}$ and thus $\mathrm{U}-\bigcup_{\alpha \in \Lambda} \mathrm{A}_{\alpha}$ is countable. Therefore, $\bigcup_{\alpha \in \Lambda} \mathrm{A}_{\alpha}$ is $\omega-\lambda$-open.

Definition 2.11: The union of all $\omega-\lambda$-open sets contained in $A \subset X$ is called the $\omega-\lambda$-interior of $A$, and is denoted by $\omega-\operatorname{Int}_{\lambda}(\mathrm{A})$. The intersection of all $\omega-\lambda$-closed sets of $\mathrm{X}$ containing $\mathrm{A}$ is called the $\omega-\lambda$-closure of $\mathrm{A}$, and is denoted by $\omega-\mathrm{Cl}_{\lambda}(\mathrm{A})$.

The proof of the following Theorems follows from the Definitions hence they are omitted.

Theorem 2.12: Let $A$ and $B$ be subsets of $(X, \tau)$. Then the following properties hold:

(i) $\omega-\operatorname{Int}_{\lambda}(\mathrm{A})$ is the largest $\omega-\lambda$-open subset of $\mathrm{X}$ contained in $\mathrm{A}$

(ii) $\mathrm{A}$ is $\omega-\lambda$-open if and only if $\mathrm{A}=\omega-\operatorname{Int}_{\lambda}(\mathrm{A})$

(iii) $\omega-\operatorname{Int}_{\lambda}\left(\omega-\operatorname{Int}_{\lambda}(\mathrm{A})\right)=\omega-\operatorname{Int}_{\lambda}(\mathrm{A})$

(iv) If $\mathrm{A} \subset \mathrm{B}$, then $\omega-\operatorname{Int}_{\lambda}(\mathrm{A}) \subset \omega-\operatorname{Int}_{\lambda}(\mathrm{B})$

(v) $\omega-\operatorname{Int}_{\lambda}(\mathrm{A}) \cup \omega-\operatorname{Int}_{\lambda}(\mathrm{B}) \subset \omega-\operatorname{Int}_{\lambda}(\mathrm{A} \cup \mathrm{B})$

(vi) $\omega-\operatorname{Int}_{\lambda}(\mathrm{A} \cap \mathrm{B}) \subset \omega-\operatorname{Int}_{\lambda}(\mathrm{A}) \cap \omega-\operatorname{Int}_{\lambda}(\mathrm{B})$.

Theorem 2.13: Let $A$ and $B$ be subsets of $(X, \tau)$. Then the following properties hold:

(i) $\omega-\mathrm{Cl}_{\lambda}(\mathrm{A})$ is the smallest $\omega-\lambda$-closed subset of $\mathrm{X}$ contained in $\mathrm{A}$;

(ii) $\mathrm{A}$ is $\omega-\lambda$-closed if and only if $\mathrm{A}=\omega-\mathrm{Cl}_{\lambda}(\mathrm{A})$;

(iii) $\omega-\mathrm{Cl}_{\lambda}\left(\omega-\mathrm{Cl}_{\lambda}(\mathrm{A})\right)=\omega-\mathrm{Cl}_{\lambda}(\mathrm{A})$;

(iv) If $\mathrm{A} \subset \mathrm{B}$, then $\omega-\mathrm{Cl}_{\lambda}(\mathrm{A}) \subset \omega-\mathrm{Cl}_{\lambda}$ (B);

(v) $\omega-\mathrm{Cl}_{\lambda}(\mathrm{A} \cup \mathrm{B})=\omega-\mathrm{Cl}_{\lambda}(\mathrm{A}) \cup \omega-\mathrm{Cl}_{\lambda}(\mathrm{B})$;

(vi) $\omega-\mathrm{Cl}_{\lambda}(\mathrm{A} \cap \mathrm{B}) \subset \omega-\mathrm{Cl}_{\lambda}(\mathrm{A}) \cap \omega-\mathrm{Cl}_{\lambda}(\mathrm{B})$.

Theorem 2.14: Let $(\mathrm{X}, \tau)$ be a topological space and $\mathrm{A} \subset \mathrm{X}$. A point $x \in \omega-\mathrm{Cl}_{\lambda}(\mathrm{A})$ if and only if $\mathrm{U} \cap \mathrm{A} \neq \phi$ for every $\mathrm{U} \in \omega \lambda \mathrm{O}(\mathrm{X}, x)$.

Theorem 2.15: Let $(X, \tau)$ be a topological space and $A \subset X$. Then the following properties hold:

(i) $\omega-\operatorname{Int}_{\lambda}(\mathrm{X}-\mathrm{A})=\mathrm{X}-\left(\omega-\mathrm{Cl}_{\lambda}(\mathrm{A})\right)$

(ii) $\omega-\mathrm{Cl}_{\lambda}(\mathrm{X}-\mathrm{A})=\mathrm{X}-\left(\omega-\operatorname{Int}_{\lambda}(\mathrm{A})\right)$ 
Theorem 2.16: If each nonempty $\omega$ - $\lambda$-open set of a topological space $X$ is uncountable, then $\omega-\operatorname{Int}_{\lambda}(\mathrm{A}) \subset \operatorname{Int}_{\lambda}(\mathrm{A})$ for each open set $\mathrm{A}$ of $\mathrm{X}$.

Proof: Clearly $\omega-\mathrm{Cl}_{\lambda}(\mathrm{A}) \subset \mathrm{Cl}_{\lambda}(\mathrm{A})$. On the other hand, let $x \in \mathrm{Cl}_{\lambda}(\mathrm{A})$ and $\mathrm{B}$ be an $\omega-\lambda$-open subset containing $x$. Then by Lemma 2.7, there exists a $\lambda$-open set $\mathrm{V}$ containing $x$ and a countable set $\mathrm{C}$ such that $\mathrm{V}-\mathrm{C} \subset \mathrm{B}$. Thus $(\mathrm{V}-\mathrm{C}) \cap \mathrm{A} \subset \mathrm{B} \cap \mathrm{A}$ and so $(\mathrm{V} \cap \mathrm{A})-\mathrm{C} \subset \mathrm{B} \cap \mathrm{A}$.

Since $x \in \mathrm{V}$ and $x \in \mathrm{Cl}_{\lambda}(\mathrm{A}), \mathrm{V} \cap \mathrm{A} \neq \phi$ and $\mathrm{V} \cap \mathrm{A}$ is $\lambda$-open since $\mathrm{V}$ is $\lambda$-open and $\mathrm{A}$ is open. $\mathrm{By}$ the hypothesis each nonempty $\lambda$-open set of a topological space $\mathrm{X}$ is uncountable and so is $(\mathrm{V} \cap \mathrm{A})-\mathrm{C}$. Thus $\mathrm{B} \cap \mathrm{A}$ is uncountable. Therefore, $\mathrm{B} \cap \mathrm{A} \neq \phi$ which means that $x \in \omega-\mathrm{Cl}_{\lambda}(\mathrm{A})$.

Corollary 2.17: If each nonempty $\lambda$-open set of a topological space $X$ is uncountable, then $\omega-\operatorname{Int}_{\lambda}(\mathrm{A})=\operatorname{Int}_{\lambda}(\mathrm{A})$ for each closed set $\mathrm{A}$ of $\mathrm{X}$.

Definition 2.18: A function $f: \mathrm{X} \rightarrow \mathrm{Y}$ is said to be quasi $\lambda$-open if the image of each $\lambda$-open set in $\mathrm{X}$ is open in Y.

Theorem 2.19: If $f: \mathrm{X} \rightarrow \mathrm{Y}$ is quasi $\lambda$-open, then the image of an $\omega-\lambda$-open set of $\mathrm{X}$ is $\omega$-open in $\mathrm{Y}$.

Proof: Let $f: \mathrm{X} \rightarrow \mathrm{Y}$ be quasi $\lambda$-open and $\mathrm{W}$ an $\omega-\lambda$-open subset of $\mathrm{X}$. Let $y \in f(\mathrm{~W})$, there exists $x \in \mathrm{W}$ such that $f(x)=y$. Since $\mathrm{W}$ is $\omega-\lambda$-open, there exists a $\lambda$-open set $\mathrm{U}$ such that $x \in \mathrm{U}$ and is countable. Since $f$ is quasi $\lambda$-open, $f(\mathrm{U})$ is open in $\mathrm{Y}$ such that $y=f(x) \in f(\mathrm{U})$ and $f(\mathrm{U})-f(\mathrm{~W}) \subset f(\mathrm{U}-\mathrm{W})=f(\mathrm{C})$ is countable. Therefore, $f(\mathrm{~W})$ is $\lambda$-open in $\mathrm{Y}$.

Definition 2.20: A collection $\left\{\mathrm{U}_{\alpha}: \alpha \in \Delta\right\}$ of $\lambda$-open sets in a topological space $\mathrm{X}$ is called a $\lambda$-open cover of a subset $\mathrm{B}$ of $\mathrm{X}$ if $\mathrm{B} \subset\left\{\mathrm{U}_{\alpha}: \alpha \in \Delta\right\}$ holds.

Definition 2.21: A topological space $\mathrm{X}$ is said to be $\lambda$ - Lindelof if every $\lambda$-open cover of $\mathrm{X}$ has a countable subcover.

A subset $\mathrm{A}$ of a topological space $\mathrm{X}$ is said to be $\lambda$ - Lindelof relative to $\mathrm{X}$ if every cover of A by $\lambda$-open sets of $\mathrm{X}$ has a countable subcover.

Theorem 2.22: Every $\lambda$ - Lindelolf space is Lindelof.

Theorem 2.23: If $X$ is a topological space such that every $\lambda$-open subset is $\lambda$-Lindelof relative to $X$, then every subset is $\lambda$-Lindelof relative to $X$.

Proof: Let $\mathrm{B}$ be an arbitrary subset of $\mathrm{X}$ and let $\left\{\mathrm{U}_{\alpha}: \alpha \in \Delta\right\}$ be $\lambda$-open cover of $\mathrm{B}$. Then the family $\left\{\mathrm{U}_{\alpha}: \alpha \in \Delta\right\}$ is a $\lambda$-open cover of the $\lambda$-open set $\cup\left\{\mathrm{U}_{\alpha}: \alpha \in \Delta\right\}$. Hence by hypothesis there is a countable subfamily $\left\{\mathrm{U}_{\alpha_{i}}: \alpha_{i} \in \mathrm{N}\right\}$ which covers $\cup\left\{\mathrm{U}_{\alpha}: \alpha \in \Delta\right\}$. This subfamily is also a cover of the set B.

Theorem 2.24: Every $\lambda$-closed subset of a $\lambda$ - Lindelof space $\mathrm{X}$ is $\lambda$-Lindelof relative to $\mathrm{X}$.

Proof: Let $A$ be a $\lambda$-closed subset of $X$ and $\tilde{U}$ be a cover of $A$ by $\lambda$-open subsets in $X$. Then $\tilde{U}^{*}=\tilde{U} \cup\{X-A\}$ is a $\lambda$-open cover of $X$. Since $X$ is $\lambda$ - Lindelof, $\tilde{U}^{*}$ has a countable subcover $\tilde{\mathrm{U}}^{* *}$ for $\mathrm{X}$. Now $\tilde{\mathrm{U}}^{* *}-\{\mathrm{X}-\mathrm{A}\}$ is a countable subcover of $\tilde{\mathrm{U}}$ for $\mathrm{A}$, so $\mathrm{A}$ is $\lambda$ - Lindelof relative to $X$.

Theorem 2.25: For any topological space $X$, the following properties are equivalent:

(i) $\mathrm{X}$ is $\lambda$-Lindelof.

(ii) Every $\lambda$-open cover of $X$ has a countable subcover.

Proof: (i) $\Rightarrow$ (ii) : Let $\left\{\mathrm{U}_{\alpha}: \alpha \in \Delta\right\}$ be any cover of $\mathrm{X}$ by $\omega-\lambda$-open sets of $\mathrm{X}$. For each $x \in \mathrm{X}$, there exists $\alpha(x) \in \Delta$ such that $x \in \mathrm{U}_{\alpha(x)}$. Since $\mathrm{U}_{\alpha}(x)$ is $\omega$ - $\lambda$-open, there exists a $\lambda$-open set $\mathrm{V}_{\alpha(x)}$ such that $x \in \mathrm{V}_{\alpha(x)}$ and $\mathrm{U}_{\alpha(x)}-\mathrm{V}_{\alpha(x)}$ is countable. The family $\left\{\mathrm{V}_{\alpha(x)}: x \in \mathrm{X}\right\}$ is a $\lambda$-open cover of $\mathrm{X}$ and $\mathrm{X}$ is $\lambda$-Lindelof. There exists a countable subset, say $\alpha_{1}(x), \alpha_{2}(x) \ldots . \alpha_{n}(x), \ldots$ such that 


$\mathrm{X}=\bigcup\left\{\mathrm{V}_{\alpha\left(x_{i}\right)}: i \in \mathrm{N}\right\} \quad$ Now, $\quad$ we $\quad \mathrm{X}=\bigcup_{i \in N}\left\{\left(\mathrm{~V}_{\alpha\left(x_{i}\right)}-\mathrm{U}_{\alpha\left(x_{i}\right)}\right) \cup \mathrm{U}_{\alpha\left(x_{i}\right)}\right\}$
$=\left(\bigcup_{i \in N} \mathrm{~V}_{\alpha\left(x_{i}\right)}-\mathrm{U}_{\alpha\left(x_{i}\right)}\right) \cup\left(\bigcup_{i \in N} \mathrm{U}_{\alpha\left(x_{i}\right)}\right)$. For each $\alpha\left(x_{i}\right), \mathrm{V}_{\alpha\left(x_{i}\right)}-\mathrm{U}_{\alpha\left(x_{i}\right)}$ is a countable set and there exists a countable subset $\Delta_{\alpha\left(x_{i}\right)}$ of $\Delta$ such that $\mathrm{V}_{\alpha\left(x_{i}\right)}-\mathrm{U}_{\alpha\left(x_{i}\right)} \subset \cup\left\{\mathrm{U}_{\alpha}: \alpha \in \Delta_{\alpha\left(x_{i}\right)}\right\}$. Therefore, we have $\mathrm{X} \subset \cup\left\{\mathrm{U}_{\alpha}: \alpha \in \Delta_{\alpha\left(x_{i}\right)}\right\}$.

(ii) $\Rightarrow$ (i) : Since every $\lambda$-open is $\omega-\lambda$-open, the proof is obvious.

\section{III. $\quad \omega-\lambda$-CONTINUOUS FUNCTION}

Definition 3.1: A function $f:(\mathrm{X}, \tau) \rightarrow(\mathrm{Y}, \sigma)$ is said to be $\omega-\lambda$-continuous if the inverse image of every open subset of $\mathrm{Y}$ is $\omega-\lambda$-open in $\mathrm{X}$.

It is clear that every $\lambda$-continuous function is $\omega-\lambda$-continuous but not conversely.

Example 3.2: Let $\mathrm{X}=\{\mathrm{a}, \mathrm{b}, \mathrm{c}\}, \tau=\{\phi,\{\mathrm{a}\}, \mathrm{X}\}$ and $\sigma=\{\phi,\{\mathrm{a}, \mathrm{c}\}, \mathrm{X}\}$. Clearly the identity function $f:(\mathrm{X}, \tau) \rightarrow(\mathrm{X}, \sigma)$ is $\omega-\lambda$-continuous but not $\lambda$-continuous.

Theorem 3.3: For a function $f:(\mathrm{X}, \tau) \rightarrow(\mathrm{Y}, \sigma)$, the following statements are equivalent:

(i) $f$ is $\omega-\lambda$-continuous;

(ii) For each point $x$ in $\mathrm{X}$ and each open set $\mathrm{F}$ of $\mathrm{Y}$ such that $f(x) \in \mathrm{F}$, there is an $\omega-\lambda$-open set $\mathrm{A}$ in $\mathrm{X}$ such that $x \in \mathrm{A}, f(\mathrm{~A}) \subset \mathrm{F}$;

(iii) The inverse image of each closed set of $Y$ is $\omega-\lambda$-closed in $X$;

(iv) For each subset $\mathrm{A}$ of $\mathrm{X}, f\left(\omega-\mathrm{Cl}_{\lambda}(\mathrm{A})\right) \subset \mathrm{Cl}(f(\mathrm{~A}))$;

(v) For each subset $\mathrm{B}$ of $\mathrm{Y}, \omega-\mathrm{Cl}_{\lambda}\left(f^{-1}(\mathrm{~B})\right) \subset f^{-1}\left(\mathrm{Cl}_{\lambda}(\mathrm{B})\right)$;

(vi) For each subset $\mathrm{C}$ of $\mathrm{Y}, f^{-1}(\operatorname{Int}(\mathrm{C})) \subset \omega-\operatorname{Int}_{\lambda}\left(f^{-1}(\mathrm{C})\right)$;

Proof: (i) $\Rightarrow$ (ii) : Let $x \in \mathrm{X}$ and $\mathrm{F}$ be an open set of $\mathrm{Y}$ containing $f(x)$.By (i), $f^{-1}(\mathrm{~F})$ is $\omega-\lambda$ open in $\mathrm{X}$. Let $\mathrm{A}=f^{-1}(\mathrm{~F})$. Then $x \in \mathrm{A}$ and $f(\mathrm{~A}) \subset \mathrm{F}$.

(ii) $\Rightarrow$ (i) : Let $\mathrm{F}$ be an open in $\mathrm{Y}$ and let $x \in f^{-1}(\mathrm{~F})$. Then $f(x) \in \mathrm{F}$. By (ii), there is an $\omega-\lambda$-open set $\mathrm{U}_{x}$ in $\mathrm{X}$ such that $x \in \mathrm{U}_{x}$ and $f\left(\mathrm{U}_{x}\right) \subset \mathrm{F}$. Then $x \in \mathrm{U}_{x} \subset f^{-1}(\mathrm{~F})$. Hence $f^{-1}(\mathrm{~F})$ is $\omega-\lambda$-open in $\mathrm{X}$.

(i) $\Leftrightarrow$ (iii) : This follows due to the fact that for any subset B of $\mathrm{Y}, f^{-1}(\mathrm{Y}-\mathrm{B})=\mathrm{X}-f^{-1}(\mathrm{~B})$.

(iii) $\Rightarrow$ (iv) : Let $\mathrm{A}$ be a subset of $\mathrm{X}$. Since $\mathrm{A} \subset f^{-1}(f(\mathrm{~A}))$ we have $\mathrm{A} \subset f^{-1}\left(\sigma_{i}-\mathrm{Cl}(f(\mathrm{~A}))\right)$ Now, $\mathrm{Cl}(f(\mathrm{~A}))$ is closed in $\mathrm{Y}$ and hence $\omega-\mathrm{Cl}_{\lambda}(\mathrm{A}) \subset f^{-1}(\mathrm{Cl}(f(\mathrm{~A})))$, for $\omega-\mathrm{Cl}_{\lambda}(\mathrm{A})$ is the smallest $\omega-\lambda$-closed set containing A. Then $f\left(\omega-\mathrm{Cl}_{\lambda}(\mathrm{A})\right) \subset \mathrm{Cl}(f(\mathrm{~A}))$.

(iv) $\Rightarrow$ (iii) : Let $\mathrm{F}$ be any closed subset of $\mathrm{Y}$. Then $f\left(\omega-\mathrm{Cl}_{\lambda}\left(f^{-1}(\mathrm{~F})\right)\right) \subset \mathrm{Cl}\left(f\left(f^{-1}(\mathrm{~F})\right)\right)$ $\subset \mathrm{Cl}(\mathrm{F})=\mathrm{F}$.Therefore, $\omega-\mathrm{Cl}_{\lambda}\left(f^{-1}(\mathrm{~F})\right) \subset f^{-1}(\mathrm{~F})$ consequently, $f^{-1}(\mathrm{~F})$ is $\omega-\lambda$-closed in $\mathrm{X}$.

(iv) $\Rightarrow(\mathrm{v})$ : Let $\mathrm{B}$ be any subset of $\mathrm{Y}$. Now, $f\left(\omega-\mathrm{Cl}_{\lambda}\left(f^{-1}(\mathrm{~B})\right)\right) \subset \mathrm{Cl}\left(f\left(f^{-1}(\mathrm{~B})\right)\right) \subset \mathrm{Cl}(\mathrm{B})$. Consequently, $\omega-\mathrm{Cl}_{\lambda}\left(f^{-1}(\mathrm{~B})\right) \subset f^{-1}(\mathrm{Cl}(\mathrm{B}))$.

(v) $\Rightarrow$ (iv): Let $\mathrm{B}=f(\mathrm{~A}) \quad$ where $\mathrm{A}$ is a subset of $\mathrm{X}$. Then, $\omega-\mathrm{Cl}_{\lambda}(\mathrm{A}) \subset \omega-\mathrm{Cl}_{\lambda}\left(f^{-1}(\mathrm{~B})\right)$ $\subset f^{-1}(\mathrm{Cl}(\mathrm{B}))=f^{-1}(\mathrm{Cl}(f(\mathrm{~A})))$. This shows that $f\left(\omega-\mathrm{Cl}_{\lambda}(\mathrm{A})\right) \subset \mathrm{Cl}(f(\mathrm{~A}))$.

(i) $\Rightarrow$ (iv) : Let $\mathrm{C}$ be any subset of $\mathrm{Y}$. Clearly, $f^{-1}(\operatorname{Int}(\mathrm{C}))$ is $\omega-\lambda$-open and we have $f^{-1}(\operatorname{Int}(\mathrm{C})) \subset \omega-\operatorname{Int}_{\lambda}\left(f^{-1}(\operatorname{Int}(\mathrm{C}))\right) \subset \omega-\operatorname{Int}_{\lambda}\left(f^{-1}(\mathrm{C})\right)$. 
(vi) $\Rightarrow$ (i) : Let $\quad \mathrm{B} \quad$ be $\quad$ an $\quad$ open $\quad$ set $\quad$ in $\quad \mathrm{Y} . \quad \operatorname{Then} \operatorname{Int}(\mathrm{B})=\mathrm{B} \quad$ and $f^{-1}(\mathrm{~B}) \subset f^{-1}(\operatorname{Int}(\mathrm{B}))$ $\subset \omega-\operatorname{Int}_{\lambda}\left(f^{-1}(\mathrm{~B})\right)$. Hence we have $f^{-1}(\mathrm{~B})=\omega-\operatorname{Int}_{\lambda}\left(f^{-1}(\mathrm{~B})\right)$. This shows that $f^{-1}(\mathrm{~B})$ is $\omega-\lambda$-open in X.

Theorem 3.4: Let $f:(\mathrm{X}, \tau) \rightarrow(\mathrm{Y}, \sigma)$ be a $\omega-\lambda$-continuous surjective function. If $\mathrm{X}$ is $\lambda$-Lindelof, then $\mathrm{Y}$ is Lindelof.

Proof: Let $\left\{\mathrm{V}_{\alpha}: \alpha \in \Delta\right\}$ be an open cover of $\mathrm{Y}$. Then, $\left\{f^{-1}\left(\mathrm{~V}_{\alpha}\right): \alpha \in \Delta\right\}$ is a $\omega-\lambda$-cover of $\mathrm{X}$. Since $\mathrm{X}$ is $\lambda$-Lindelof, $\mathrm{X}$ has a countable subcover, say $\left\{f^{-1}\left(\mathrm{~V}_{\alpha_{i}}\right)\right\}_{i=1}^{\infty}$ and $\mathrm{V}_{\alpha_{i}} \in\left\{\mathrm{V}_{\alpha}: \alpha \in \Delta\right\}$ Hence $\left\{f^{-1}\left(\mathrm{~V}_{\alpha_{i}}\right): \alpha \in \Delta\right\}$ is a countable subcover of $\mathrm{Y}$. Hence, $\mathrm{Y}$ is Lindelof.

Definition 3.5:[1] A function $f: \mathrm{X} \rightarrow \mathrm{Y}$ is said to be $\lambda$-continuous if the inverse image of each open subset of $\mathrm{Y}$ is $\lambda$-open in $\mathrm{X}$.

Corollary 3.6: Let $f:(\mathrm{X}, \tau) \rightarrow(\mathrm{Y}, \sigma)$ be a $\omega-\lambda$-continuous (or $\lambda$-continuous) surjective function. If $\mathrm{X}$ is $\lambda$ - Lindelof, then $\mathrm{Y}$ is Lindelof.

Definition 3.7: A function $f: \mathrm{X} \rightarrow \mathrm{Y}$ is said to be $\omega-\lambda^{*}$-continuous if the inverse image of each $\lambda$-open subset of $\mathrm{Y}$ is $\omega-\lambda$-open in $\mathrm{X}$.

The proof of the following Theorem is similar to Theorem 3.4 and hence omitted.

Theorem 3.8: Let $f:(\mathrm{X}, \tau) \rightarrow(\mathrm{Y}, \sigma)$ be a $\omega-\lambda^{*}$-continuous surjective function. If $\mathrm{X}$ is $\lambda$-Lindelof, then $\mathrm{Y}$ is $\lambda$-Lindelof.

Theorem 3.9: $\mathrm{A} \omega-\lambda$-closed subset of a $\lambda$-Lindelof space $\mathrm{X}$ is $\lambda$-Lindelof relative to $\mathrm{X}$.

Proof: Let $\mathrm{A}$ be an $\omega-\lambda$-closed subset of $\mathrm{X}$. Let $\left\{\mathrm{U}_{\alpha}: \alpha \in \Delta\right\}$ be a cover of A by $\lambda$-open sets of X. Now for each $x \in \mathrm{X}-\mathrm{A}$, there is a $\lambda$-open set $\mathrm{V}_{x}$ such that $\mathrm{V}_{x} \cap \mathrm{A}$ is countable. Since $\left\{\mathrm{U}_{\alpha}: \alpha \in \Delta\right\} \cup\left\{\mathrm{V}_{x}: x \in \mathrm{X}-\mathrm{A}\right\}$ is a $\lambda$-open cover of $\mathrm{X}$ and $\mathrm{X}$ is $\lambda$-Lindelof, there exists a countable subcover $\left\{\mathrm{U}_{\alpha_{i}}: i \in \mathrm{N}\right\} \cup\left\{\mathrm{V}_{x_{i}}: i \in \mathrm{N}\right\}$. Since $\bigcup_{i \in \mathrm{N}}\left(\mathrm{V}_{x_{i}} \cap \mathrm{A}\right)$ is countable, so for each $x_{j} \in \cup\left(\mathrm{V}_{x_{i}} \cap \mathrm{A}\right)$, there is $\quad \mathrm{U}_{\alpha\left(x_{j}\right)} \in\left\{\mathrm{U}_{\alpha}: \alpha \in \Delta\right\} \quad$ such $\quad$ that $\quad x_{j} \in \mathrm{U}_{\alpha\left(x_{j}\right)} \quad$ and $j \in \mathrm{N}$. Hence $\left\{\mathrm{U}_{\alpha_{i}}: i \in \mathrm{N}\right\} \cup\left\{\mathrm{U}_{\alpha\left(x_{j}\right)}: j \in \mathrm{N}\right\}$ is a countable subcover of $\left\{\mathrm{U}_{\alpha}: \alpha \in \Delta\right\}$ and it covers A. Therefore, A is $\lambda$-Lindelof relative to $\mathrm{X}$.

Corollary 3.10: If a topological space $\mathrm{X}$ is $\lambda$-Lindelof and $\mathrm{A}$ is $\omega$-closed (or $\lambda$-closed), then $\mathrm{A}$ is $\lambda$ - Lindelof relative to $X$.

Definition 3.11: A function $f: \mathrm{X} \rightarrow \mathrm{Y}$ is said to be $\lambda$-closed if $f(\mathrm{~A})$ is $\omega-\lambda$-closed in $\mathrm{Y}$ for each $\lambda$-closed set A of X.

Theorem 3.12: If $f: \mathrm{X} \rightarrow \mathrm{Y}$ is an $\omega-\lambda$-closed surjection such that $f^{-1}(y)$ is $\lambda$-Lindelof relative to $\mathrm{X}$ and $\mathrm{Y}$ is $\lambda$-Lindelof, then $\mathrm{X}$ is $\lambda$-Lindelof.

Proof: Let $\left\{\mathrm{U}_{\alpha}: \alpha \in \Delta\right\}$ be any $\lambda$-open cover of $\mathrm{X}$. For each $y \in \mathrm{Y}, f^{-1}(y)$ is $\lambda$-Lindelof relative to $\mathrm{X}$ and there exists a countable subset $\Delta_{1}(y)$ of $\Delta$ such that $f^{-1}(y) \subset \cup\left\{\mathrm{U}_{\alpha}: \alpha \in \Delta_{1}(y)\right\}$. Now, we put $\mathrm{V}(y)=\mathrm{Y}-f(\mathrm{X}-\mathrm{V}(y))$. Then, since $f$ is $\omega-\lambda$-closed, $\mathrm{V}(y)$ is an $\omega-\lambda$-open set in $\mathrm{Y}$ containing $y$ such that $f^{-1}(\mathrm{~V}(y)) \subset \mathrm{U}(y)$. Since $\mathrm{V}(y)$ is $\omega-\lambda$-open, there exists a $\lambda$-open set $\mathrm{W}(y)$ containing $y$ such that $\mathrm{W}(y)-\mathrm{V}(y)$ is a countable set. For each $y \in \mathrm{Y}$, we have $\mathrm{W}(y) \subset(\mathrm{W}(y)-\mathrm{V}(y)) \cup \mathrm{V}(y)$ and hence $f^{-1}(\mathrm{~W}(y)) \subset f^{-1}(\mathrm{~W}(y)-\mathrm{V}(y)) \cup f^{-1}(\mathrm{~V}(y)) \subset f^{-1}(\mathrm{~W}(y)-\mathrm{V}(y)) \cup \mathrm{U}(y)$.

Since $\mathrm{W}(y)-\mathrm{V}(y)$ is a countable set and $f^{-1}(y)$ is $\lambda$ - Lindelof relative to $\mathrm{X}$, there exists a countable set $\Delta_{1}(y)$ of $\Delta$ such that $f^{-1}(\mathrm{~W}(y)-\mathrm{V}(y)) \subset \cup\left\{\mathrm{U}_{\alpha}: \alpha \in \Delta_{2}(y)\right\}$ and hence $f^{-1}(\mathrm{~W}(y))$ $\subset\left(\cup\left\{\mathrm{U}_{\alpha}: \alpha \in \Delta_{2}(y)\right\}\right) \cup \mathrm{U}(y)$. Since $\{\mathrm{W}(y): y \in \mathrm{Y}\}$ is a $\lambda$-open cover of the $\lambda$-Lindelof space $\mathrm{Y}$, 
there exist countable points of $\mathrm{Y}$, say $y_{1}, y_{2}, \ldots y_{n} \ldots$ such that $\mathrm{Y}=\cup\left\{\mathrm{W}\left(y_{i}\right): i \in \mathrm{N}\right\}$. Therefore, we obtain $\mathrm{X}=\bigcup_{i \in \mathrm{N}} f^{-1}\left(\mathrm{~W}\left(y_{i}\right)\right)=\bigcup_{i \in \mathrm{N}}\left(\left(\bigcup_{\alpha \in \Delta_{2}\left(y_{i}\right)} \mathrm{U}_{\alpha}\right) \cup\left(\bigcup_{\alpha \in \Delta_{1}\left(y_{i}\right)} \mathrm{U}_{\alpha}\right)\right)=\left\{\mathrm{U}_{\alpha}: \alpha \in \Delta_{1}\left(y_{i}\right) \cup \alpha \in \Delta_{2}\left(y_{i}\right), i \in \mathrm{N}\right\}$.

This shows that $\mathrm{X}$ is $\lambda$-Lindelof.

\section{References}

[1] F.G.Arenas, J.Dontchev and M.Ganster, On $\lambda$-closed sets and dual of generalized continuity, $Q \& A$ Gen.Topology, 15, (1997), 3-13.

[2] M.Caldas, S.Jafari and G.Navalagi, More on $\lambda$-closed sets in topological spaces, Revista Columbiana de Matematica, 41(2), (2007), 355-369.

[3] H.Maki, Generalized $\Lambda$-sets and the associated closure operator, The special issue in commemoration of Prof. Kazusada IKEDA's Retirement, (1.Oct, 1986), 139-146. 